\title{
COMMISSION 51: BIOASTRONOMY: SEARCH FOR EXTRATERRESTRIAL LIFE
} (BIOASTRONOMIE: RECHERCHE DE LA VIE EXTRATERRESTRE)

\author{
PRESIDENT: K. J. Meech \\ VICE-PRESIDENT: A. Boss \\ ORGANIZING COMMITTEE: F. Capaccioni, P. Ehrenfreund, C. Eiroa, \\ W. Hubbard, D. Latham, E. Martín, M. Mayor, D. Morrison, R. Norris, J. \\ Tarter
}

\section{IAU GENERAL ASSEMBLY COMMISSION 51 BUSINESS MEET- ING - MINUTES. July 17 2003, 09:00-12:00 the Sydney Convention Centre (room PM1).}

Present:

Meech (President - Chair), A'Hearn, Ehrenfreund, Jugaku, Morrison, Quirrenbach, Tarter, Div. III President, I. Williams and 2 additional observers.

\section{Divisional Reorganization:}

The meeting began with a report by M. A'Hearn and I. Williams about the divisional reorganization. The new IAU bylaws will emphasize the divisions, which will exist forever, whereas the commissions will not. The commissions will be created, continued or disbanded every triennium, with the idea that commissions should not be continued automatically, that only the active commissions will survive. Under the new system, the divisions and commissions will have organizing committees (OC) elected by the membership prior to the general assembly. The $\mathrm{OC}$ will make a recommendation of officers to the division, and this will no longer need EC approval. In addition, any working groups appointed will disappear after 3 years unless there is a proposal to continue them. Williams noted that the division's role should be to fight for the structure that we want. He envisions that we set up the structure during the next 3 years, then in the following 3 years put it in place with a new OC and officers. Given that we have to changes, it should be in the direction that we want, and our commission should be thinking about what direction we want during the triennium. As a suggestion, Williams proposed a possible commission on small bodies, which might have subgroups, and another which would incorporate other topics (such as that encompassed by the current Commission 51), perhaps called "Habitable Worlds". There was some discussion of this, C51 members not wanting our identity to be lost.

Election of new members:

The list passed to Commission 51 from the IAU was approved. In addition, M. A'Hearn requested to become a member of commission 51, and Abdul

Alasabti had sent in an email request. Their acceptance was proposed and accepted with acclamation by those present at the meeting. 


\section{Election of Executive:}

The OC gave strong support to Alan Boss to be the incoming VP for C51, and the next President. Alan has a been active in areas of Bioastronomy, and is currently the head of the working group on Extrasolar Planetary Systems. Alan's election carried by acclamation.

\section{Scientific Organising Committee:}

Because it was felt that many of the current OC members have not been active, and because of the OC only Meech and Tarter were present at the business meeting, it was proposed that the current members of the $\mathrm{OC}$ be polled to assess their continued interest in remaining on the OC. In addition, 2 new members of the OC were proposed and accepted by acclamation at the meeting: D. Morrison and P. Ehrenfreund. The tradition in the past had been to rotate OC members off after serving for 2 triennia, however this was only a guideline. In view of the possible current changes to the commission structure, we felt that adopting a policy about OC membership at this point would be premature.

\section{President's Report:}

Outgoing President, S. Bowyer, was unable to attend this meeting, so the incoming President, K. Meech, gave the report. The report began with a summary of upcoming meetings relevant to $\mathrm{C} 51$.

One of the major activities of C51 has been to organize a triennial Bioastronomy meeting. The last meeting was held in Australia on Hamilton Island in 2002, as IAU Symposium 213. Just prior to the 2002 meeting, plans for a proposed 2005 meeting in France fell through, but fortunately at the 2002 meeting Iceland agreed to host the meeting in 2004. The date was moved a year earlier both to avoid the IAU GA and to get out of sync with the ISSOL meeting scheduled for July 2005 , since it had been difficult for C51 members to attend both meetings. Meech, who is on both the Bioastronomy 2004 SOC and LOC reported that the planning for the meeting is well underway. The SOC consists of 15 members (from the US, Europe, Mexico, Australia and Iceland), chaired by A. Boss, and the LOC, chaired by Thorsteinn Thorsteinsson (Iceland), consists of 11 members. The meeting theme, "Habitable Worlds", will focus on (i) Extrasolar Habitable Worlds, (ii) Origin and Evolution of Terrestrial Life, (iii) Life Elsewhere in the Solar System; (iv) Life in Extrasolar Planetary Systems; and ( $v$ ) Intelligent Life Beyond the Solar System. The program will consist of contributed and invited talks, and 20 speakers have accepted invitations to speak. The meeting will be held at the University of Iceland Conference Center in Reykjavík, the Háskólabió from July 12-16, 2004. Four scientific field trips associated with the meeting are planned, which will highlight astrobiologically relevant geology, including sites of subglacial eruptions, the largest historical lava flows on Earth, and regions of catastrophic flooding similar to ancient Mars. The LOC is currently seeking funding for this meeting, and has a target of $\$ 250$ for the registration fee. The abstracts will be published in the Astrobiology Journal, and there will be a special issue for conference papers. There will be no special proceedings volume. All the information about the meeting may be found at the website: http://www.os.is/ thor/bioastronomy04/

B. Reipurth gave a report on the plans for the Protostars and Planets meeting $V$ (PPV) to be held Oct. 22-29, 2005, at the Hilton Waikoloa Village hotel on the big island of Hawaii. The meeting is in the initial stages of planning, with a hotel contract in place holding a block of 350 rooms for the expected attendance of 500 .

Morrison reported on the NASA Ames biennial AbSciCon meeting. This meeting is open to the general international community, with typically around 700 registrants. This meeting is held in alternate years with the NASA Astrobiology Institute annual 
meeting; the next one will be in March 2004. Morrison said that the NAI would like to have a science representative from $\mathrm{C} 51$ to be on the SOC for the AbSciCon meeting.

\section{Other business:}

At previous C51 business meetings, the issue of the name of the commission has been brought up. Many in the commission felt it was important to change the commission name to be more inclusive. One proposal was to drop the "Search for Extraterrestrial Life" and just have the name "Bioastronomy". There were too few people attending the C51 business meeting this year to get into a good discussion about this, so it will be discussed via email, in conjunction with members of the working group for Extrasolar Planets (WGESP) during the next triennium. At issue was also the role of the WGESP within C51 and the new IAU structure.

In conjunction with this, Meech noted that many people active in bioastronomy are not members of C51, and many in C51 are not apparently active in bioastronomy. It was felt that the commission should be more pro-active in recruiting IAU members who are active in the field. One way to do this will be set up some scientific goals to be accomplished this triennium.

The meeting closed at 12:00

\section{IAU GENERAL ASSEMBLY COMMISSION 51 SCIENTIFIC MEET- ING - MINUTES. July 21 2003, 09:00-12:30 the Sydney Convention Centre (room HM4).}

For our second program time slot the commission decided to have a science program since we didn't need additional time to discuss commission business. The science program was very well attended, with about 50 present. The program included a series of short review talks to summarize progress in the field, followed by the latest news regarding Bioastronomy observations, experiments, theory and facilities. While there was an organized program, there was also time at the end for people from the audience to get up and present materials. The program of talks is listed below:

- Short review talks summarizing progress in Bioastronomy

- Extrasolar planet research and latest discoveries / Update on Optical SETI - Tarter

- Results from the NASA Astrobiology CAN 3 selections - Meech

- New results from Organics in Space - Ehrenfreund

- Latest News

- Status of the Allen Telescope Array - Tarter

- Faulkes Telescope and Astrobiology Outreach - Meech

- Mars Simulation Chamber - Ehrenfreund

- IR comet spectra and the ISM - Woodney

- Stellar metallicity -

K. Meech

President of the Commission 